\title{
Instituciones culturales y la inmaterialidad del arte contemporáneo
}

\author{
doi: 10.33264/rpa.202001-15 \\ Simón Arévalo Hernández \\ Licenciado en Ciencias de la Información, UCSC
}

\section{Resumen}

Los avances tecnológicos han traído consigo numerosos cambios en los ámbitos de la cultura y las artes, puntualmente a partir de ciertas obras desarrolladas con códigos informáticos y dispuestos a través del internet y sus dispositivos de acceso. No obstante, la institucionalidad cultural se ha quedado atrás a la hora de sumar estas piezas en sus colecciones de manera adecuada.

El presente artículo trata sobre esta problemática y de cómo instituciones como las bibliotecas y los museos se podrían volver irrelevantes a la hora de cumplir su misión documental, de conservación y de difusión ante estas situaciones, particularmente, cuando esa misma inmaterialidad y falta de soporte físico se vuelve parte de una esencia y narrativa artística. Se citan y proponen lineamientos que la institucionalidad cultural puede considerar y adoptar para enfrentar estas complejidades que ponen en juego su relevancia con el devenir de la tecnología y las nuevas formas de expresión artística.

Palabras clave: hipercultura, metamodernidad, bibliotecología, museología, arte contemporáneo, arte de los nuevos medios, net.art

\section{Abstract}

Technological advances have brought numerous changes in the fields of culture and the arts, specifically those based on certain works developed with computer codes and arranged through the Internet and its access devices. However, cultural institutions have lagged behind when it comes to adding these pieces to their collections in an appropriate way.

This article deals with this problem and how institutions such as libraries and museums might become irrelevant when it comes to fulfilling their documentary, conservation and dissemination mission in these situations, particularly when that same immateriality and lack of physical support become part of an artistic and narrative essence. Guidelines are cited and proposed that cultural institutions can consider and adopt in order to face these complexities that put their relevance at stake with the evolution of technology and new forms of artistic expression. 
Keywords: hyperculture, metamodernity, library science, museology, contemporary art, new media art, net.art

\section{Introducción}

Las problemáticas abordadas en el presente artículo se enmarcan a partir de las nuevas realidades de conservación artística relacionadas con la tecnología y la manera que ésta afecta al arte mismo. Para entender las complejidades asociadas a este tema es necesario interiorizarse en el concepto de la hipercultura, idea vinculada a la globalización y a la unificación cultural mundial producto de factores como la revolución de las tecnologías de la información, la organización de redes transnacionales y la ampliación de las industrias culturales (Lipovetsky, 2011). La cultura tradicional se afirmaba como particular y local, fragmentada e inmutable; la hipercultura en cambio se despliega en la universalidad cosmopolita, del cambio perpetuo y funciona a través de lo inmemorial. Los espacios disminuyen y el tiempo se acelera en el denominado "cibertiempo global" (que no implica la desaparición de las distancias y culturas locales). Se generan identidades nuevas y múltiples en "un mundo donde las fronteras entre el arte y la moda, entre la vanguardia y lo comercial están en disolución permanente" (Lipovetsky, 2011), donde los artistas no dudan en utilizar métodos del capitalismo no solamente para promocionar su trabajo, sino también para reinterpretarlos y apropiar sus herramientas como comentarios y dialécticas irónicas y post-irónicas.

Esta forma de cultura remodela el universo material de la producción y el comercio: Las marcas, la moda y la cultura popular tienden entonces a adquirir una connotación estética y semiótica, que reivindican lenguajes y narrativas originalmente comerciales y triviales que ponen en duda o fin a las contradicciones culturales del capitalismo, al apropiarse de sus lenguajes, métodos y narrativas para crear experiencias estéticas.

Tras la globalización y masificación del acceso a internet, la tecnología digital reformuló todos los aspectos de la contemporaneidad, con lo que eventualmente da paso a nuevas formas de expresiones artísticas. El vínculo de la cultura con la tecnología no es nuevo, ésta última ha reinventado y puesto en cuestión las formas en que se percibe el arte y su hacer. Tema que se convirtió en punto de interés en los estudios auxiliares del arte (museología, bibliotecología, ciencias de la conservación, etc.) al tratar, por ejemplo, la reproductibilidad técnica y sus problemáticas ya instauradas por Walter Benjamin.

Esto se complejiza con el arribo y desarrollo de los medios de comunicación masivos, provocando también una tendencia a la deslocalización. Esta hiper-tecnologización 
del arte abordaría nuevos problemas y situaciones propias de lo inmaterial: el cómo estas tendencias y cuestionamientos constantes pueden enfrentarse a formas de expresión cultural que desafían tanto los paradigmas de la conservación, como aquellos sobre conceptos de "comunidad", tan utilizados por la museología crítica.

Dorado et. al., postulan que las nuevas artes nacidas en la hipercultura representan el espíritu posmoderno: desechan los paradigmas modernos de lo patrimonial y museable y superponen al patrimonio intangible como paradigma, evidencia y expresión de las sociedades. Asimismo, señalan la necesidad que presenta la museología de auxiliarse de otras disciplinas científicas para la resolución de problemas para reafirmar su posición y validarse dentro del entorno posmoderno.

Las instituciones relacionadas con las ciencias documentales y comúnmente relacionadas con el mundo de las artes han sido principalmente los museos y las bibliotecas, que se proyectaban a partir de un edificio, una colección y un público, todos elementos que interactúan dentro de lo material y por ende eran concebidas como estructuras físicas y dependientes de esas limitaciones, idea que permaneció inmóvil inclusive tras ciertos movimientos críticos posteriores. Estas miradas son continuas al paradigma de la disciplina auxiliar de la documentación, con ideas como el almacenamiento y la conservación puesto que almacenamos información en virtud de una utilidad que le ha sido conferida a una obra. El museo y la biblioteca, en conjunto con su rol educativo, prestan servicios para satisfacer necesidades de información y así generar nuevos conocimientos: Almacenar, clasificar y disponer.

Puntualmente en el caso de los museos, es a partir de 1968 durante el auge de los movimientos contraculturales en que es criticada la visión pasiva de la institución y la consolidada noción del museo-templo, pues se decalró de que debían responder adecuadamente a las sociedades a las que pertencen. Surgen entonces nuevas lecturas a finales del siglo XX, como la nueva museología y la museología crítica donde, y en común a la museología tradicional, las colecciones que definen al museo se basan en objetos reunidos de manera intencional y originada en una misma fuente. Lo museable y lo almacenable -tanto en un sentido de puesta en valor, como de posibilidades técnicas y de intencionalidad artística- se trataban de elementos tangibles o intangibles pero registrados a partir de soportes documentales fotografía, audio y video-. Bajo esta perspectiva, los museos estarían obligados a repensar su papel basado en los principios de las corrientes museológicas críticas, sumando todos aquellos paradigmas y elementos de los cambios producidos por la tecnología y sobre cómo ésta cambia la forma en que los espectadores se relacionan con, en este caso, el arte (Rivero, 2017). 
No obstante, estos movimientos poco previeron el nacimiento y crecimiento que ocasionaría el Internet en las disciplinas documentales. A partir de la masificación de su acceso a mediados de la década de los 2000, se produce un incremento en la cantidad de información generada, y por ende, disponible. Esto conlleva al concepto de sociedad de la información; aspectos que se consideran antecedentes ante la problemática de lo inmaterial y su conservación.

\section{Esas nuevas artes}

El net.art (género artístico considerado base inmaterialidades producto de la hipercultura) introdujo trabajos que utilizaban al internet como medio y un lenguaje en sí mismo, vale decir, algo más que una plataforma para mostrar obras; este arte entonces crea y crece en sentido y contexto a partir la web, donde Internet define tanto el lugar como el tiempo y la razón de su existencia (Christou, 2017). Vale la pena también hacer la distinción entre los conceptos arte en internet y net.art. Como arte en internet se puede definir a cualquier obra que pueda ser visualizada en la web y que sea considerada o puesta en valor como arte; por ejemplo, una imagen de "Las meninas" de Velásquez ilustrando un artículo de Wikipedia. Por otro lado, el concepto del net.art hace referencia a obras de arte creadas para y desde internet. Sin embargo, en ocasiones la línea entre ambos puede ser difícil de separar.

Estas manifestaciones encuentran fundamento también en la interactividad, puesto que exigen que "el espectador sea parte vital de la experiencia estética y puede interactuar vívidamente con la misma". A mediados de los noventa, una serie de artistas comienzan a emplear el internet como soporte de obras y proyectos, contexto en el que surge el net.art autorreferencial, obras basadas formalmente en códigos de programación HTML.

Este arte está creado por artistas que se desenvuelven en el ciberespacio y están relacionados con el mundo online y una forma de tiempo propia. Como describe Christou (2017) "Desafía la vida física, pelea su propia extinción, y continuamente redefine su mundo y sus asociaciones". Este tiempo digital, en su movilidad, cambia la forma de hacer y evaluar el arte, junto con sugerir que deberíamos reinventar la manera en que pensamos el arte en general, puesto que también otorga nuevas posibilidades del medio: velocidad en la comunicación, en la difusión, distribución de la información y la posibilidad de feedback.

Como la producción cultural nace de la fluidez, el net.art contemporáneo, del denominado post-internet, transforma la manera en que se percibe el arte, desafiando el tiempo, duración e integridad de sus obras. Cabe mencionar que esta 
idea del post-internet, más que un "después" (por usar el componente post), el término es utilizado para describir un "diálogo crítico constante a partir de las interacciones humanas ( $y$ por qué no decirlo, de inteligencia artificial) generadas a partir del internet" (Christou, 2017).

Esta similitud encuentra un punto de convergencia con la aparición de la performance digital, en que las tecnologías juegan un rol activo, no sólo como herramienta sino también como plataforma, integrando nuevos dispositivos y modos de expresión como la realidad virtual y la robótica (Ávila, 2017). Por ejemplo performances donde se utilizan recursos como la transmisión en vivo vía satélite, fusionando de esta manera la performance, los eventos en vivo y las tecnologías telemáticas.

Existen algunas características propias de la reproductibilidad que permite el internet; ya que no existe alguna imagen o imaginario original. Una obra, inclusive con restricciones legales, puede ser copiada o descargada de la web tantas veces como sus usuarios lo deseen. Como comenta Christiane Paul: "La obra de arte en la era de la reproducción digital da por sentado el remezclado y la copia instantánea. Sin degradar del original a sus múltiplos". Esto se encuentra relacionado con la idea de que el arte digital supone una ventana de libertad artística y sociopolítica, al ser más compleja una censura y un control en los contenidos de Internet, al menos en las democracias liberales occidentales, lugar donde se produce la mayoría de sus contenidos.

Tal vez el elemento más reconocido en masa del término web $\mathbf{2 . 0}$ son las redes sociales, que en el arte han facilitado enormemente su difusión pero limitan otros elementos distintivos y que eran seminales en el net.art, como la programación y el hecho de desenvolverse en el lienzo del HTML.

Por otro lado, no debe descartarse que estas redes posibilitan el dar pie a metadiscursos, donde el formato preestablecido del sitio web o la aplicación (por ejemplo, los artistas que publican en Instagram) puede usarse de por sí como recurso artístico: La conocida frase de que la obra requiere de la interacción del receptor para que se de por culminada, adquiere en estos casos un carácter más hondo, puesto que el espectador ahora es capaz de no sólo ser un espectador pasivo, sino también de interactuar con ella y el artista, ser parte de su creación, descargarla y compartirla. Un momento en que los artistas actúan menos como intérpretes, narradores o curadores y más como participantes completamente implicados. Ellos exhiben sus obras en "lugares" donde también curan (comparten) otros trabajos, inspiran y reciben un feedback inmediato sobre su trabajo. 
Las plataformas del internet también han hecho que los entes productores (artistas) se manifiesten a través de un "doble digital”, que, de manera similar al concepto avatar o al anglicismo internet persona, puede ser definido como un reflejo tecnológico del cuerpo vivo, "una imagen que refleja la forma visual idéntica y el movimiento en tiempo real del performer"(Dixon, 2007). Barbaño y Muñoz-Muñoz (2017) sostienen que internet -algo más usual antes de la llegada y masificación de las redes sociales- oculta las identidades en las que la sociedad suele clasificar a las personas, propiciando el anonimato y la multiplicidad de la autoría, similares y en directa relación a movimientos que ubican esta característica como base para sus movimientos culturales post y metamodernos, en que los artistas utilizan pseudónimos difíciles de localizar mediante buscadores (por ejemplo, utilizando caracteres Unicode) y ambiguos en materias de género (tanto en el concepto anglosajón de genre como de gender) tal como el caso de los movimientos ciberculturales y transhumanistas.

Similarmente, se ofrecen ciertas ventajas y nuevos paradigmas que solucionan algunas problemáticas asociadas a las artes tradicionales. Colectivos como las artistas mujeres e identidades de género no binarias han sido pioneras en este tipo de arte al encontrar la libertad de tener menos carga simbólica que en los medios convencionales (Aguilar, 2011). Este arte inclusive es citado como un "lugar desestabilizador en las grandes narrativas biológicas, tecnológicas y evolucionistas occidentales" (Haraway, 2005). Junto a lo anterior, en el net.art las mujeres artistas "delegan la posición de su cuerpo en medios y soportes convencionales a la red, siendo internet el medio" (Rubio, 2003).

La vida de las artes no materiales como las performances y los happenings, dependen de la intencionalidad de los artistas y como se ha mencionado, esta dependencia también se da por las técnicas de documentación y archivísticas de su tiempo, lo que convierte a este arte en una relación altamente dependiente con las capacidades de sus medios de preservación. La tecnología y sobre todo aquella ligada a las interacciones sociales y comunicativas, influyen directamente en la cultura, transformando los soportes y los medios de difusión.

En sus nociones clásicas, tanto el museo, el archivo y la biblioteca deben conservar elementos fijos y estables, algo que es imposible en el arte digital los nuevos medios. Preservar la actividad de una obra viva y activa es complejo, en muchos casos de imposible consecución (Rivero, 2017). Consideremos por ejemplo algún posteo en una red social que posee un apartado de comentarios activo. Estos comentarios, las interacciones, el compartir estas obras en perfiles, su descarga y otros fenómenos, 
podrían perfectamente ser formulados como parte de una obra en sí, incluso su posterior modificación, edición y eliminación; llevando al plano de la

Web 2.0, aquellas posibilidades que aprovechan al máximo lo que la web puede ofrecer. También es necesario de que la museología se plantee de que si es conveniente la conservación, pues ésta podría atentar contra las características esenciales de las obras que ven al net.art como un arte performativo, que puede ser interpretado como una sub-rama de aquellas artes cuya temporalidad transcurre en el momento.

\section{Problemáticas}

El internet se vislumbraba para algunos autores como una red casi anárquica y sin jerarquizaciones, en donde la información y sus usuarios fluyen en direcciones múltiples y simultáneas (Rivero, 2017), por eso mismo tenía la complejidad, al poseer esta fluidez, de no poseer una suerte de encapsulamiento y fijación de la información. Los errores en la preservación digital suelen ser repentinos e inconscientes, respaldados en esta ilusión de que la información en internet "siempre está" por el simple hecho de que los usuarios promedio desconocen la existencia de servidores y de que esta información está de alguna manera almacenada en un soporte físico, dependiente de técnicas de conservación de seguridad.

Sin embargo, esta situación se ve de manera inversa por autores como Christou (2017), quien -sobre el arte de los nuevos medios-, señala que existe efectivamente una materialidad en esas formas de arte: su material es virtual y una vez entrado al mundo online, estará con vida de alguna manera, inclusive si sus enlaces están rotos o si son removidos por sus creadores, puesto que es -casi- imposible eliminar cada rastro de la información dispuesta online. Asimismo, no existe garantía alguna de que estos sitios no han comunicado esta información a terceras personas. El ciclo de vida de una obra del post internet reformula y cambia completamente los conceptos establecidos sobre el arte mismo y su vínculo con las ciencias de la documentación y la archivística. Complejizando su labor, que ya era considerada un desafío al tratarse de la conservación y descripción catalográfica de obras físicas (por ejemplo, si es necesaria su descripción contextual y conceptual, elementos subjetivos y por tanto, ajenos a la documentación tradicional).

Se produce una llamada conciliación entre perspectivas: la voluntad de preservar este tipo de obras para que puedan ser entendidas, disfrutadas y contextualizadas a futuro sin cometer una distorsión que impida entender la experiencia propuesta originalmente por los artistas.

De igual manera, la institucionalidad cultural debe enfrentarse a un dilema 
inesperado de si estos trabajos deben estar dispuestos en un lugar físico o su lugar debe ser exclusivamente lo online, puesto que el arte del post internet puede entenderse como asociado con los datos, a la información que existe - y que tal vez, sólo deba existir- online.

Algunos autores perciben una contradicción entre esta intangibilidad de las tecnologías y los requerimientos convencionales que ofrecen los espacios físicos de los museos, bibliotecas y archivos. Roy Ascott (1996), citado en Barranha (2016) define por ejemplo, que el concepto de museo digital es un oxímoron, puesto que lo digital se refiere a fluidez, inmaterialidad y transformación, mientras que "museo" se relaciona con solidez, estabilidad y permanencia. Acá es donde la biblioteca y el museo clásicos se ponen en cuestión pero en un sentido sobre creación: ¿Qué pueden aportar estas limitadas plataformas para la nueva creación artística?

Por ejemplo, las innovaciones técnicas son cada vez menos duraderas; los artefactos suelen tener una vida útil cada vez más breve y por tanto los artistas deben enfrentarse -ya sea solucionando o sacando provecho conceptual y/o estético- a la obsolescencia programada, que no sólo afecta a los dispositivos, sino también a otros elementos propios de la transmisión de datos multimedia, como pueden ser los softwares, las aplicaciones móviles y las maneras a transmitir datos.Y es que la preservación de estas artes también posee una dependencia externa, ya no de la institucionalidad cultural ni de los artistas mismos, sino de componentes comerciales, como la continuidad de ciertas tecnologías, servidores, servicios de hosting y elementos del mercado, regulados y dependiente de las industrias y sus tendencias. Los medios, el hardware, software, los dispositivos de los artistas, los espacios (en este caso los museos y las bibliotecas) o el mismo público de manera personal y privada, condicionan particularmente la experiencia artística (Rivero, 2017). No es como ver una fotografía de la Mona Lisa en el Louvre a partir de nuestro celular, sino nuestro teléfono es el museo, la sala, la plaza pública. Esto está condicionado a las realidades económicas y sobre la obsolescencia de estos mismos dispositivos.

Independiente de que los dispositivos futuros y que serán utilizados para visualizar net.art del presente sean superiores y cuenten con mayor capacidad, resolución o calidad, la experiencia no será la misma. ¿Es algo que se hace actualmente? Los museos de arte, al exhibir, por ejemplo, piezas de videoarte de los años ochenta ¿Exhiben estas obras en televisores de la época? ¿Si no lo hacen es perder autenticidad? ¿Puede ser, esta suerte de "flujo de dispositivos" parte de la experiencia artística misma? ¿Qué tan diferente es a montar una pintura en distintos escenarios, galerías o salas y dispuesta junto con la luminaria de su época? La obra digital entonces no puede escapar de la anacronía. 
Lo digital está fijo a un código y a información procesada en bits, por ende, debe materializarse para hacerse visible y para ello debe ayudarse de elementos tecnológicos que son tangibles y físicos. La contrariedad en este caso ocurre al presentarse ciertos problemas técnicos, como las incompatibilidades entre codificadores y lectores de información. Rivero (2017) menciona que se proponen procesos como la migración, emulación, reinterpretación y recreación. No obstante, todas estas etapas incluyen ciertos riesgos. Por ejemplo, la copia de una obra de un dispositivo a otro implica necesariamente una pérdida de la información y por consiguiente, de su calidad. Esta problemática entre original-copia es casi similar a una exposición sobre patrimonio arquitectónico que consta de fotografías y maquetas. Se exhibe una reproducción de, no la obra completa. Igual ejemplo se puede encontrar en las muestras de performance dispuestas a partir de fotografías y videos en museos.

Estos avances también producen un problema; en sus inicios el net.art abarcaba imágenes simples en formatos de jpg, gif, png o sitios web en html, hoy en cambio los recursos tecnológicos hacen que con la misma facilidad de antes los artistas realicen sus trabajos en formatos más complejos y de mayor tamaño, al ser vídeos o archivos de CGI que ocuparían gigabytes de memoria. Los buscadores de internet también juegan un rol determinante en los problemas y los conflictos que tanto artistas como espectadores tienen en el internet contemporáneo (Christou, 2017), puesto que suelen disponer la información de acuerdo a sus propios términos, ya sea generados por algoritmos siguiendo tendencias de otros usuarios, como aquellos que siguen ciertas agendas publicitarias o relacionadas con restricciones gubernamentales.

\section{Propuestas}

Como solución a la inmaterialidad, a mediados de los años noventa se desarrolló el concepto de las galerías y bibliotecas virtuales en internet, con el objetivo de democratizar a través de una nueva alternativa la posibilidad de exponer trabajos sin las trabas monetarias, burocráticas e inclusive ideológicas de las instituciones tradicionales. Cuando se piensa en museos virtuales, el concepto apuntaba principalmente a la reproducción digital de colecciones físicas -como el Google Arts \& Culture y su correspondiente aplicación móvil-, no obstante, sus métodos y plataformas, al ser usualmente respaldadas por instituciones de prestigio, pueden servir de referente para futuros portales dedicados a artes de nuevos medios.

Ejemplo de ello están los proyectos pasados de dam.org, el Adobe Museum of Digital Media y el caso del Guggenheim Virtual Museum, que concebía al museo virtual como un objeto navegable, consciente de la arquitectura de lo líquido, lo fluido y lo mutable. 
A pesar de su corta existencia (1999-2002), este proyecto trajo consigo una perspectiva nueva y original sobre hacer museos, pavimentando el camino a futuras construcciones basadas en la web.

Después del desarrollo de la web 2.0, dos visiones complementarias empezaron a coexistir en las áreas de los museos online y el arte digital. Una fue la idea de archivos y bases de datos y en la otra, la noción del museo como un proyecto global y "contenedor de contenidos" que den cuenta del pasar cultural, incluyendo proyectos nacidos desde plataformas digitales, vale decir que no son subentidades de museos tradicionales o físicos, sino que su misma constitución, desarrollo e identidad transcurre en Internet. Esto se suma a la interrogante de cómo la arquitectura museal puede lidiar con lo intangible, inestable y líquido (Barranha, 2016) del arte digital.

Este acercamiento a la arquitectura del museo, asume una paradoja entre lo virtual y lo tangible, asumiendo que el post-internet y la hipercultura, son, por naturaleza, un constructo híbrido: Lo virtual como elemento que genera autoconciencia de la realidad y sus fronteras.

Rivero (2017), en este sentido plantea que en estas formas de expresión cultural el concepto clave es la continuidad por sobre el principio tradicional de conservación. Esto quiere decir que el creador reconozca la obra como suya y que ésta sea comprensible y utilizable por un usuario, en un contexto explicativo y dando uso y continuidad del documento, haciendo que la obra sea capaz de reproducirse en diversos contextos, dispositivos y lenguajes de información y programación. No obstante, esto se torna más complejo cuando en las obras existe una intencionalidad hacia lo efímero y se plantean con caducidad planificada o inclusive, cuando el propio artista es indiferente o contrario a la conservación de su creación. Por ejemplo, cómo se puede disponer en una galería algo cuya esencia está hecha para un portal y contexto-web determinado. En ese sentido, cobra más fuerza la idea de que la alternativa más viable es mediante la reproducción.

La institucionalidad cultural deberá considerar estas formas de expresión como disciplinas que guiarán el resto del universo artístico a futuro, y de que es importante para entender cómo será y se proyectará la evolución en la arquitectura de los museos. Los medios digitales independientes permiten una valoración honesta e inmediata de propuestas estéticas nuevas o reivindicativas, a diferencia de la "burocracia" que puede tener la institucionalidad cultural. Estas ventajas obligan a que las instituciones bibliotecarias y museales y que velan por el patrimonio artístico asuman una permanente y casi necesaria interacción entre las interfaces físicas y online. 
Es un aprendizaje mutuo, sobre qué puede aprender la conservación artística tradicional de los nuevos medios y sus artes y manifestaciones culturales asociadas. Tal vez su lugar es ése: entre medio, en lo que puede desarrollar uno y en otro o en ambos al mismo tiempo. Esto no sólo se limita los museos de arte, puesto que la nueva manera de construir historia, cultura e inclusive ciencia se está dando también a partir de la inmaterialidad de lo virtual.

\section{Referencias}

Avila, S. (2017). Registro y difusión del performance artístico en la era digital. Index, revista de arte contemporáneo, (4), 99-106.

Barbaño, M. B., \& Muñoz-Muñoz, A. M. (2017). La construcción de la imagen de las mujeres: net. art y medios de comunicación. Historia y Comunicación Social, 22(1), 249.

Barranha, H. (2016). Between the Virtual and a Hard Place: The dilemma of digital art museums. In EVA.

Christou, E. (2017). The Digital Time of Internet Art. Signal Effects: Digital Ecologies and the Anthropocene.

Dorado, Y. D., Rodríguez, A. M., \& Columbié, R. L. (2015). Museología y Ciencias de la Información: notas sobre sus vínculos. Bibliotecas. Anales de Investigación, (11), 50-63.

Linares Columbié, R. (2005). Ciencia de la información: su historia y epistemología. Rojas Eberhard.

Lipovetsky, G. (2011). El reino de la hipercultura: cosmopolitismo y civilización occidental. El occidente globalizado. Un debate sobre la cultura planetaria.

Rivero Moreno, L. D. (2017). Inmaterialidades. Problemas de conservación del arte de los nuevos medios. De Arte. Revista de Historia del Arte, (16), 227-238.

\section{Simón Arévalo Hernández}

Licenciado en Información Documental de la Universidad Católica de la Santísima Concepción. Diplomado en Museos y Museología, Universidad de Santiago de Chile. ORCID: 0000-0002-0187-6085 